\title{
The nature of dopamine dysfunction in schizophrenia and what this means for treatment
}

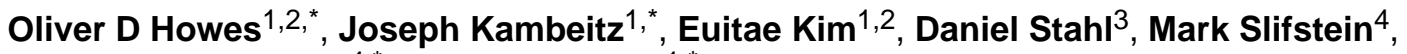 \\ Anissa Abi-Dargham ${ }^{4, *}$, and Shitij Kapur ${ }^{1, *}$ \\ ${ }^{1}$ Department of Psychosis Studies, Box 67, Institute of Psychiatry - Kings College London, \\ Camberwell, London, SE5 8AF, UK \\ ${ }^{2}$ Psychiatric Imaging Group, MRC Clinical Sciences Centre - Imperial College London, \\ Hammersmith Hospital, London, W12 0NN, UK \\ ${ }^{3}$ Department of Biostatistics, Institute of Psychiatry - Kings College London, Camberwell, London, \\ SE5 8AF, UK \\ ${ }^{4}$ Department of Psychiatry, Columbia University, New York State Psychiatric Institute, Unit 31, \\ 1051 Riverside Drive, New York, NY 10032, USA
}

\begin{abstract}
Context-Current drug treatments for schizophrenia are inadequate for many patients and, despite five decades of drug discovery, all use the same mechanism-dopamine D2 receptor blockade. Understanding the pathophysiology of the disorder is thus likely to be critical to the rational development of new treatments for schizophrenia.
\end{abstract}

Objective-To investigate the nature of the dopaminergic dysfunction in schizophrenia using meta-analysis of in vivo studies.

Data sources-The MEDLINE, EMBASE and PsychINFO databases were searched for studies from January 1, 1960, to July 1, 2011.

Study selection-Forty-four studies were identified that compared in vivo striatal dopaminergic function in 618 patients with schizophrenia with 606 controls using positron emission tomography or single photon emission computed tomography.

Data extraction-Demographic, clinical and imaging variables were extracted from each study and effect sizes determined for the measures of dopaminergic function. Studies were grouped into those of presynaptic function, and dopamine transporter and receptor availability. Sensitivity analyses were conducted to explore the consistency of effects and the effect of clinical and imaging variables.

Data synthesis-There was a highly significant elevation $(\mathrm{p}<0.0001)$ in presynaptic dopaminergic function in schizophrenia with a large effect size (Cohen's $d=0.79$ ). There was no evidence of alterations in dopamine transporter availability. There was a small elevation in D2/3 receptor availability (Cohen's $d=0.26$ ), but this was not evident in drug-naïve patients and was influenced by the imaging approach used.

Conclusions-The locus of the largest dopaminergic abnormality in schizophrenia is presynaptic-affecting dopamine synthesis capacity, baseline synaptic dopamine levels and dopamine release. Current drug treatments - which primarily act at D2/3 receptors - fail to target

Correspondence should be addressed to: Dr Oliver Howes; tel: 00442078480080; fax: 00442083831783; oliver.howes@kcl.ac.uk.

* These authors contributed equally 
these abnormalities. Future drug development should focus on the control of presynaptic dopamine synthesis and release capacity.

\section{Introduction}

Schizophrenia remains one of the leading causes of global disease burden in adults despite over fifty years of drug development. ${ }^{1}$ Understanding its neurobiology is critical for future rational drug discovery. ${ }^{2,3}$ The dopamine hypothesis of schizophrenia was first proposed over thirty years ago on the basis of indirect evidence. It received support from studies of post-mortem brain tissue that found increased striatal D2/3 receptor density and dopamine levels in schizophrenia and from studies of CSF dopamine and its metabolites (see ${ }^{4-6}$ and reviews ${ }^{7,8}$ ). However post-mortem studies are not able to measure some aspects of the dopaminergic function, such as dopamine release, and are potentially biased by the effects of antipsychotic treatment and agonal events, whilst the CSF studies were inconsistent and unable to provide insights into the regional aspects of dopamine dysfunction. ${ }^{9-11}$ The introduction of positron emission tomography (PET) and single photon emission computed tomography (SPECT) imaging enabled the investigation of in vivo cerebral dopamine neurotransmission free of these limitations. ${ }^{11-13}$

PET and SPECT imaging has been used to investigate dopaminergic parameters in schizophrenia, beginning with studies of D2/3 receptors ${ }^{14,15}$ and later covering presynaptic function, including dopamine synthesis capacity and dopamine release, and transporters ${ }^{16-19}$ (see supplementary materials for further background on these approaches). To our knowledge there has not been a previous meta-analysis of the presynaptic or dopamine transporter findings in schizophrenia, and, since the previous D2/3 meta-analysis in drug free/naive patients ${ }^{20}$, there have been a large number of new studies which approximately doubles the sample size.

The purpose of our meta-analysis is to synthesise the PET and SPECT imaging findings on dopaminergic function in schizophrenia, and to consider their implications for the treatment of schizophrenia. We focus on the striatum because this has the highest density of dopamine projections in the brain ${ }^{21}$, and dopaminergic dysfunction here can be reliably imaged and has been linked to the severity of symptoms, response to treatment and the onset of the disorder. ${ }^{22-25} \mathrm{We}$ group findings into studies of presynaptic dopaminergic function (dopamine synthesis capacity, dopamine release and synaptic dopamine levels), dopamine transporter and dopamine receptor availability. The studies of dopamine synthesis capacity are grouped with those of dopamine release and synaptic dopamine levels (which use pharmacological challenges that either deplete or release dopamine from presynaptic terminals) because animal ${ }^{26-28}$ and in vivo human evidence ${ }^{29}$ indicates that they index related aspects of dopaminergic function. However, the results are also given separately for these different methodological approaches for comparison.

Researchers can view the study data and add future studies on our open-access database and wiki (http://www.schizophreniadatabase.kcl.ac.uk).

\section{Methods}

\section{Data sources and study selection}

The entire PubMed, PsychINFO and MEDLINE electronic databases were searched from $1^{\text {st }}$ January 1960 up to 1 st July 2011. To be included in the meta-analysis a paper needed to report in vivo PET or SPECT imaging findings on striatal dopaminergic function in patients with schizophrenia and a control group, including the mean and standard deviations for both groups. Current antipsychotic treatment was an exclusion criterion for the studies of 
dopamine receptors, because this affects dopamine receptor binding potential. ${ }^{30}$ See supplementary figure 1 for search results and supplementary materials for further details on the search and inclusion/exclusion criteria.

\section{Data extraction}

The main outcome measure was the difference in the dopaminergic imaging parameter between healthy controls and patients with schizophrenia.

The following additional information was extracted from all the studies: authors, year of publication, population characteristics of the control and patient groups (group size, age, gender, antipsychotic use, diagnosis, symptom ratings), characteristics of the PET or SPECT imaging (radiotracer, other methodological factors reported), scanner characteristics (scanner type and resolution), and modeling method.

\section{Data analysis}

Separate meta-analyses were conducted for the studies of presynaptic dopaminergic function, dopamine receptors and dopamine transporters. The standardized effect sizes of the individual studies were entered in a random-effects meta-analytic model. ${ }^{31,32}$ The summary effect sizes (Cohen's $d$ ) were computed using a restricted maximum-likelihood estimator. ${ }^{33}$ Publication bias was assessed using funnel plots. Heterogeneity was assessed by calculating the $\mathrm{I}^{2}$ value ( $\mathrm{I}^{2}$ values $<50 \%$ indicate low-moderate heterogeneity whilst values $>50 \%$ indicate moderate-high heterogeneity). ${ }^{34}$ Leave-one-out sensitivity analyses were conducted. Sources of bias and heterogeneity were evaluated using meta-regression (for publication year and age) and sub-group analyses (for antipsychotic treatment, illness duration and imaging approach). A significance level of $\mathrm{p}<0.05$ (two-tailed) was used for all analyses. See supplementary materials for further methodological details.

\section{Results}

\section{Pre-synaptic dopaminergic function}

Seventeen studies described in fifteen publications (three reported in one paper ${ }^{25}$ ) met inclusion criteria. We excluded one of our papers ${ }^{35}$ from the main analysis because it reports additional data on the same subjects included in a previous report ${ }^{36}$, although the data are used in sub-analyses where there is no subject duplication, and another paper because the comparator group was siblings. ${ }^{37}$ Overall the studies include a total of 231 patients and 251 controls. Study details are reported in supplementary tables 1 and 2.

There was a significant elevation in schizophrenia, with a summary effect size of $d=0.79$ (figure $1,95 \%$-CI: 0.52 to $1.07, \mathrm{z}=5.65, \mathrm{p}<0.0001$ ).

\section{Heterogeneity and sensitivity analyses}

The $\mathrm{I}^{2}$ value was $39.92 \%$ (95\%-CI for $\mathrm{I}^{2}: 0$ to $77.03 \%$ ), indicating low to moderate heterogeneity between studies. Whilst the regression test for funnel-plot asymmetry was not significant $(\mathrm{z}=1.52, \mathrm{p}=0.13)$, visual inspection of the funnel-plot suggested asymmetry, indicating possible publication bias. The trim-and-fill analysis indicated 3 potentially missing studies on the left side of the funnel-plot (all with large standard errors and small effect sizes, see supplementary figure 2). Nevertheless, the summary effect size remained large and highly significant after correcting for these putatively missing studies (corrected effect size: $d=0.67 ; \mathrm{z}=4.55, \mathrm{p}<0.0001,95 \%$-CI: 0.37 to $0.94, \mathrm{I}^{2}=48.83 \%, 95 \%$-CI of $\mathrm{I}^{2}$ : 10.17 to $81.01 \%)$. 
The summary effect size reached significance in all cases in the leave-one-out analysis, with summary effect sizes varying from $d=0.73$ to $d=0.86$ (all $\mathrm{p}<0.0001$ ).

Meta-regression indicated there was no influence of the year of publication $(\beta=-0.02$, $\left.\mathrm{F}_{1,13}=0.99, \mathrm{p}=0.34\right)$, or subject age $\left(\beta=0.004, \mathrm{~F}_{1,12}=0.015\right.$, $\left.\mathrm{p}=0.90\right)$. In case current antipsychotic drug treatment was confounding the results, the meta-analysis was rerun exclusively for studies of drug-free/drug-naïve patients. This showed a significant elevation in drug free/drug naïve patients compared to controls ( $\mathrm{n}=13, d=0.69 ; 95 \%$-CI: 0.36 to 1.01 , $\mathrm{z}=4.14, \mathrm{p}<0.0001, \mathrm{I}^{2}=46.46 \%, 95 \%$-CI for $\mathrm{I}^{2}: 0$ to $\left.85.31 \%\right)$. The effect sizes for the studies grouped by antipsychotic treatment are shown in figure 2 .

The effect sizes grouped by imaging method are shown in supplementary figure 3 . There was a significant elevation in schizophrenia when the meta-analysis was restricted to the studies using radiolabeled-DOPA $(\mathrm{n}=11 ; d=0.78 ; 95 \%$-CI: 0.38 to $1.18, \mathrm{z}=3.82, \mathrm{p}=0.0001$, $\mathrm{I}^{2}=52.62 \%, 95 \%$-CI for $\mathrm{I}^{2}: 3.19$ to $84.02 \%$ ). The effect sizes were similarly positive in the studies of dopamine release ( $d=1.35, d=0.88$, and, for the Laruelle et al, 1999 report combining 3 cohorts: $d=0.91$ ) and in the studies of synaptic dopamine levels ( $d=1.09$ and $d=0.61$ ), but there were too few studies to rerun the meta-analysis separately for these approaches.

\section{Dopamine transporter}

Eleven studies met inclusion criteria, providing data on a total of 152 patients and 132 healthy controls. Study details are shown in supplementary tables 3 and 4.

There was no evidence of a significant difference between patients with schizophrenia and controls (figure $3, d=-0.34,95 \%$-CI: -0.75 to $+0.07, \mathrm{z}=-1.64, \mathrm{p}=0.10$ ).

\section{Heterogeneity and sensitivity analyses}

The $\mathrm{I}^{2}$ value was $64.04 \%$ (95\%-CI of $\mathrm{I}^{2}: 25.22$ to $88.99 \%$ ), indicating moderate-large heterogeneity between studies. There was no evidence for publication bias (regression test for funnel plot asymmetry: $\mathrm{z}=-1.75, \mathrm{p}=0.08$; no missing studies estimated by trim-and-fill analysis; see supplementary figure 4 for the funnel-plot), and no significant effect of year of publication $\left(\beta=-0.01, \mathrm{~F}_{1,9}=0.04, \mathrm{p}=0.85\right)$, or age $\left(\beta=0.02, \mathrm{~F}_{1,9}=0.25, \mathrm{p}=0.63\right)$ on the effect size. The sub-group analyses found no group differences (see supplementary materials).

\section{Dopamine receptors}

D2/3 receptors-Twenty-two studies met inclusion criteria, providing data on 337 patients and 324 healthy controls (nb: data from ${ }^{15}$ form part of a subsequent larger dataset $^{38}$ ). The population characteristics and methodological details of the studies are shown in supplementary tables 5 and 6 .

There was a significant elevation in schizophrenia with a summary effect size of $d=0.26$ (figure 4, 95\%-CI: 0.001 to $0.52, \mathrm{z}=1.97, \mathrm{p}=0.049$ ).

Heterogeneity and sensitivity analyses-The $\mathrm{I}^{2}$ value was $63.93 \%$ (95\%-CI of $\mathrm{I}^{2}$ : $39.65-84.81 \%$ ), indicating moderate-large heterogeneity between studies. There was no evidence for publication bias (regression test for funnel plot asymmetry: $\mathrm{z}=1.32, \mathrm{p}=0.19$; no missing studies estimated by trim-and-fill analysis; see supplementary figure 5 for the funnel-plot), and no significant effect of year of publication $\left(\beta=-0.03, \mathrm{~F}_{1,19}=2.27, \mathrm{p}=0.15\right)$ or age $\left(\beta=0.01, F_{1,18}=0.34, p=0.57\right)$ on the effect size. 
In the leave-one-out analysis the effect sizes varied from $d=0.18$ to $d=0.32$ (with p-values from $p=0.11$ to $p=0.01$ respectively), and were not significant on 14 of the 22 iterations. We repeated the meta-analysis including one study ${ }^{39}$ initially excluded due to the relatively short antipsychotic drug wash-out period and found a non-significant effect size of $d=0.25$ (95\%-CI: $-0.01-0.51, \mathrm{z}=1.8753, \mathrm{p}=0.061, \mathrm{I}^{2}=62.75 \%, 95 \%$-CI of $\mathrm{I}^{2}: 38.65-84.13 \%$ ). The sub-group analyses identified no significant difference between patients and controls in studies exclusively of antipsychotic-naïve patients or that used benzamide radiotracers, whilst significant differences were found in studies including patients who had received prior antipsychotic treatment or that used butyrophenone radiotracers (see supplementary materials for these analyses and comparisons of illness duration between sub-groups).

Other dopamine receptors-We identified four studies of D1 receptor availability in untreated patients ${ }^{40-43}$ - too few to permit meta-analysis. None of these found a significant difference in striatal D1 availability between patients with schizophrenia and controls, although one study ${ }^{43}$ found a trend towards an increase in antipsychotic-naïve but not drugfree patients (see supplementary materials for overview).

\section{Striatal sub-regions}

We repeated the meta-analyses for the caudate and putamen separately. In the studies of presynaptic function, there was a significant elevation in schizophrenia for the putamen ( 8 studies, $d=0.51, \mathrm{z}=2.72, \mathrm{p}=0.007,95 \%$-CI: $0.14-0.88$ ) but not the caudate. There were no significant differences in the caudate or putamen between patients and controls in the studies of dopamine transporter or D2/3 receptor availability (see supplementary materials for details).

\section{Discussion}

The main findings from our meta-analyses are that presynaptic dopaminergic function is altered in schizophrenia, with a large effect size $(d=0.79)$, whilst there is no difference in dopamine transporter availability and a small elevation in D2/3 receptor availability, although the latter was not consistent. These findings are summarised schematically in figure 5 .

\section{Methodological considerations}

One methodological consideration common to all meta-analyses is that they are limited by the quality of the studies that are included. We have included all relevant studies rather than applying quality screening as this may introduce other biases, although this involves pooling findings from studies using different radiotracers, scanners, data collection, and methods of pharmacokinetic analysis. We have summarised these variables (supplementary tables 1-6) to enable readers to make judgements about individual studies. Whilst including all studies has the advantage of reducing selection biases and increasing the generalizability of findings, there is a risk of diluting effects.

There was low-moderate heterogeneity in the studies of presynaptic dopaminergic function, suggesting that there is consistency across studies. However there was moderate to large heterogeneity in the studies of dopamine transporter and D2/3 receptor availability. Potential sources for this were evaluated in secondary analyses and are discussed below.

Nevertheless, as the random effects model used in the meta-analyses does not assume homogeneity of effects, our findings should be robust to heterogeneity.

Presynaptic dopaminergic function-Whilst the trim-and-fill analysis indicated there may be missing studies, the elevation in patients remained large and highly significant after 
correcting for putatively missing studies. There was a highly significant and large effect size in all the iterations of the leave-one-out analysis, indicating that the elevation in presynaptic dopaminergic function was not dependent on the inclusion of any one study. We found a large positive effect size when the meta-analysis was restricted to studies using radiolabelled DOPA, and, although there were insufficient studies to permit separate metaanalyses, there were similar positive effect sizes in the studies that used AMPT or amphetamine challenges, suggesting the elevation is consistent across technique. The elevation was evident when studies of patients currently taking antipsychotic treatment were excluded from the meta-analysis, indicating that antipsychotic treatment is unlikely to explain the effect. We cannot, however, exclude the possibility that prior treatment had a persisting effect in the studies of drug free patients; although figure 2 indicates that in absolute terms the effect sizes were at least as great in the studies of drug naïve patients as in patients who had received prior treatment, suggesting that this is not the case.

The radiolabeled-DOPA studies used several different analytic and imaging methods, including the simple ratio approach which does not account for many of the complexities of radiolabeled-DOPA analysis, and is highly dependent on scanning duration ${ }^{44}$ - factors that may contribute to the negative effect size in the only study to use this approach. ${ }^{45}$ Nevertheless, that the elevation in schizophrenia was evident across studies using a variety of methods and analytic approaches suggests it is robust.

The elevation in presynaptic dopaminergic function could be due to an increased density of dopamine terminals in the striatum. However, this interpretation is unlikely for two reasons: first, there is no evidence of a similar elevation in dopamine transporter availability in our meta-analysis or in the vesicular monoamine transporter (both in vivo markers of dopamine neuron terminal density) ${ }^{46,47}$, and, second, dopamine neuron numbers are not elevated in post-mortem samples. ${ }^{48}$ This thus indicates that the increased dopamine synthesis capacity and dopamine release reflects functional changes rather than increased neuronal density. Whilst elevated dopamine synthesis capacity could reflect increased enzyme activity in compensation for reduced L-DOPA or dopamine levels, this interpretation is not consistent with the evidence that synaptic dopamine levels and dopamine release respectively are also increased and positively correlated. ${ }^{35}$ Together the presynaptic studies thus suggest there is increased dopaminergic activity reflected in increased dopamine synthesis capacity, and dopamine release..$^{35}$ This is consistent with evidence of increased turnover of striatal dopamine in schizophrenia. ${ }^{49}$ Further work is needed to determine if dopamine synthesis capacity is related to dopamine release in schizophrenia, as has been found for synaptic dopamine and dopamine release, ${ }^{35}$ and if other aspects of dopaminergic function (eg: conversion of tyrosine to L-DOPA, and dopamine catabolism) are also abnormal.

Dopamine transporter availability-There was no evidence of publication bias. Antipsychotic treatment is unlikely to explain our finding because most of the patients in the dopamine transporter studies were drug-naive, and the lack of difference between patients and controls was also evident when the studies of treated patients were excluded. A likely source of the heterogeneity between studies is the number of different radiotracer imaging approaches used, although we were not able to formally assess this. Differences in clinical characteristics, such as variation in the severity and phase of illness and drug free intervals, are evident between studies (see supplementary tables) and may be a further source of heterogeneity between studies.

Dopamine receptor availability-There was no evidence of publication bias. There was no significant difference between patients and controls on fourteen of the twenty-two iterations of the leave-one-out analysis, indicating that the finding of a difference in the meta-analysis is not robust. In the sensitivity analyses we could not detect a difference 
between patients and controls when the meta-analysis was restricted to purely drug-naive patients, or when it was restricted to patients who had received prior treatment scanned with benzamide radiotracers. The two studies that used ergot radiotracers included a mixture of drug-naïve and prior treated patients and found no difference between patients and controls, in line with the findings with benzamide radiotracers. However, when the meta-analysis was restricted to butyrophenone radiotracers there was an elevation in patients. Interestingly this was not evident in the one butyrophenone study exclusively of drug-naïve patients. These further analyses thus suggest that the imaging approach used and the inclusion of patients who had received prior antipsychotic treatment are likely to contribute to the inconsistency in the meta-analysis. Other differences in clinical characteristics may also contribute to thisin particular: duration of illness (which was shorter in the drug-naive patients), whether illness duration included the prodrome, and the nature and severity of symptoms (see supplementary table 6).

There are differences in the pharmacokinetic properties of the different radiotracers, and the analytic methods used to characterise them, as well as their pharmacodynamic characteristics $^{50-52}$, so it is not possible to disentangle which of these factors might underlie the effect of imaging approach on our findings. For example, in comparison with the benzamide radiotracer raclopride, in membrane, slice and cell preparations the butyrophenone radiotracers NMSP and spiperone have shown paradoxical binding decreases following dopamine depletion ${ }^{53,54}$ and either increases or no overall change following stimulated release ${ }^{53-55}$. Some ${ }^{55}$ though not all studies ${ }^{56}$ have found that spiperone has a greater tendency to bind to internalized receptors than does raclopride. NMSP and spiperone also have higher affinity for D2/3 receptors than raclopride $\left(\mathrm{K}_{\mathrm{d}}\right.$ values in the picomolar range compared to the nanomolar range for raclopride) and have slower kinetics ${ }^{50}$, which make it more difficult to obtain quantitative estimates from short-duration PET studies and necessitates the use of a different kinetic model for analysis. ${ }^{15,57}$

When evaluating the sensitivity analyses it is also important to consider that the risk of typeII errors is increased when the number of studies is reduced, and there is an inevitable decrease in the precision of the estimate. This is reflected in the wide confidence intervals for the drug-naive and drug-free groupings, and therefore the finding of a lack of a significant difference in the drug-naive studies needs to be seen in the context of the reduced power to find such a difference. Finally elevated baseline synaptic dopamine in schizophrenia could potentially make group differences harder to detect. Nevertheless, overall one can conclude that whilst there was a small elevation in D2/3 receptor availability it was not a consistent finding, and, was not present in drug-naïve patients, although some caveats remain.

\section{Implications for the dopamine hypothesis of schizophrenia}

Our findings provide in vivo evidence to support the dopamine hypothesis of schizophrenia. Early versions of this hypothesis could only conjecture the nature of the abnormality. ${ }^{58}$ This meta-analysis provides evidence to specify that the major dopaminergic abnormality in schizophrenia is a presynaptic one, affecting dopamine synthesis capacity and release, and that, in contrast, the overall effect on D2/3 receptor availability is small. This view is supported by findings of elevated dopamine synthesis capacity in drug naïve individuals in the prodrome to schizophrenia ${ }^{24}$, and of a further increase associated with the onset of the psychotic disorder. ${ }^{59}$ There is also evidence of specificity as this presynaptic dopaminergic dysfunction is not seen in non-psychotic affective and anxiety disorders (see review ${ }^{16}$ ). Whilst we were unable to examine symptoms in our meta-analyses, the challenge studies link elevated dopamine release to positive rather than negative symptoms. ${ }^{17,36}$ 
Whilst our findings support proposals that dopaminergic dysfunction is a final common pathway to psychosis, they do not address the issue of what drives the presynaptic striatal alterations. One candidate is decreased D1 mediated dopaminergic neurotransmission in the frontal cortex (see review ${ }^{60}$ and $^{61,62}$ ). Another candidate, supported by preclinical models and some human findings ${ }^{63-65}$, is glutamatergic dysfunction.

Our finding that dopamine transporter availability is unaltered indicates that there is no elevation in transporter levels that might compensate for elevated dopamine release. It may also explain the later age of onset of schizophrenia in women than men, as women tend to have higher dopamine transporter availability than men, which naturally declines with age in both sexes. ${ }^{66}$ Although our findings indicate that transporter availability is unaltered, it remains possible that transporter function is altered in schizophrenia.

As we focussed on the striatum, it is not possible to know if our presynaptic findings are specific to the striatum or also relevant to dopaminergic projections to other brain regions and future work will need to evaluate the extra-striatal dopamine system. Our analyses of striatal sub-regions suggest that the pre-synaptic elevation may be localised to the putamen. However, these findings should be considered as exploratory as not all studies provided data and the resolution of scanners varied markedly (see supplementary table 1). The putamen localisation contrasts with recent findings focusing on functional, as opposed to purely anatomical, sub-regions of the striatum, which have suggested that the dopaminergic dysfunction is localised in a part of the caudate nucleus that is linked to associative cortical regions. ${ }^{67,} 68$ Unfortunately, there were too few studies for the functional sub-regions to be examined in our meta-analysis and studies using high resolution scanners are warranted to examine sub-regional effects further.

\section{Implications for treating schizophrenia}

The current drug treatments for schizophrenia were discovered prior to notions of dopamine as a neurotransmitter, or our ability to measure its function in vivo in humans. They were the outcome of empiricism and serendipity, rather than rational drug design based on pathophysiology. It has transpired that the major mode of action of all currently licensed antipsychotic drugs is blockade of D2 receptors. ${ }^{9,}{ }^{69}$ However, our meta-analysis indicates that by blocking D2 receptors, current drugs are acting down-stream of the locus of the largest dopaminergic abnormality in the disorder. Thus, whilst antipsychotics suppress overall neurotransmission, they fail to target the major dopaminergic abnormality. Furthermore, our finding that the D2/3 alterations were not present in drug-naïve patients suggests that D2/3 receptor alterations are not intrinsic to the illness, but are secondary to prior antipsychotic treatment. Although studies are needed to test this after accounting for the factors discussed above, this interpretation is consistent with animal evidence that antipsychotics result in D2/3 receptor up-regulation, ${ }^{70}$ and evidence that withdrawing antipsychotic drugs in humans uncovers elevated D2/3 receptor availability. ${ }^{71}$ It is not surprising then that when antipsychotics are stopped (usually by the patient) and there is both nothing to suppress the dysregulated presynaptic dopaminergic system, and a potentially supersensitive post-synaptic receptor system, there is a high risk of relapse.

Our findings indicate that rather than focussing exclusively on post-synaptic receptors, future treatments should target the presynaptic control of dopamine synthesis and release. Interestingly one of the first effective drug treatments for schizophrenia was reserpine, ${ }^{72}$ and more recent data show that AMPT administration is associated with a rapid and profound reduction in psychotic symptoms. ${ }^{36}$ As both these drugs deplete presynaptic dopamine stores there is thus proof of principle that acting on the presynaptic dopaminergic system can treat psychosis. However, whilst presynaptic dopamine depletion seems logical from a pathophysiological perspective, it raises a technical challenge as dopamine and 
norepinephrine share part of the same synthetic pathway. Thus treatments that interfere with dopamine also risk affecting norepinephrine synthesis leading to undesirable side-effects. Therefore future efforts at presynaptic modulation will need to go beyond the simple depletion of dopamine or blockade of its synthesis as the cost-benefit ratio of this is unlikely to be therapeutically viable. They will also probably need to show some regional selectivity if they are to avoid altering dopamine neurotransmission in the frontal cortex, and potentially worsening negative symptoms and cognitive impairments, both of which have been linked to frontal cortical D1 receptor availability in schizophrenia. ${ }^{42}$

Interestingly patients who respond less well to antipsychotic drugs have been found to show lower synaptic dopamine levels ${ }^{36}$, and findings indicate treatment resistant patients show normal dopamine synthesis capacity. ${ }^{73}$ These findings suggest that psychotic symptoms in some patients may be unrelated to dopaminergic function, at least as indexed by these imaging techniques.

Although we did not find a major alteration in dopamine transporter or D2/3 receptor availability, there could nevertheless be other functional alterations. In fact, this is indirectly suggested by findings that patients with schizophrenia are supersensitive to the

psychotogenic effects of the D2 receptor agonist apomorphine when given at high doses. ${ }^{74}$ Interestingly, when apomorphine is given at low doses, which are thought to have a preferential presynaptic action to reduce dopaminergic transmission, it has an antipsychotic effect. ${ }^{75} \mathrm{D} 2$ receptors may exist in forms with differing affinities for dopamine, and it has been proposed that there is an excess of the high affinity form in schizophrenia. ${ }^{74}$ However, the first in vivo study in schizophrenia using a radiotracer selective for the high affinity form found no evidence of alterations, although a significant caveat is that this radiotracer also shows appreciable binding to D3 receptors. ${ }^{76}$ Notwithstanding this, other aspects of D2/3 receptor function, such as internalisation or signal transduction, or the function of other dopamine receptors could be abnormal in schizophrenia and warrant investigation in patients. If these or other aspects of D2 function are abnormal this would suggest new drug targets, and, even if D2 function is unaltered, finding new ways to intervene at this level could still be useful to counteract the effects of presynaptic dysfunction on dopamine neurotransmission.

An attractive feature of the current findings is that the pathophysiological target - increased dopamine synthesis capacity and dopamine release - can now be measured in preclinical models and humans using exactly the same molecular imaging techniques, as has been done for dopamine transporters and D2/3 receptors ${ }^{77}$. So, whilst most of the animal models used to develop antipsychotics in the past have had to rely on indirect measures (such as amphetamine-induced locomotion, or conditioned avoidance response abolition), the current findings provide a pathophysiological target that can be directly measured in animals. With advances in small animal imaging and experimental human studies it should be possible to induce the precise presynaptic abnormality in animal models, and to measure the response to new medications in animals and in experimental human models in the same way.

\section{Conclusions}

There is consistent evidence of presynaptic dysfunction in schizophrenia with a large effect size, but no evidence of a compensatory increase in dopamine transporter availability to buffer the system. D2/3 receptor up-regulation is small and not detected in antipsychotic naïve patients. These findings suggest that drug development should target the presynaptic regulation of dopamine synthesis and release. 


\section{Supplementary Material}

Refer to Web version on PubMed Central for supplementary material.

\section{Acknowledgments}

Dr Howes has had full access to the data and conducted the analyses with Mr Kambeitz.

Funding: Medical Research Council UK (MRC grant MC_US_A655_0002_01 to Dr Howes); the Biomedical Research Council (BRC) UK.

\section{References}

1. Rossler W, Salize HJ, van Os J, Riecher-Rossler A. Size of burden of schizophrenia and psychotic disorders. Eur Neuropsychopharmacol. 2005; 15(4):399-409. [PubMed: 15925493]

2. Lewis DA, Gonzalez-Burgos G. Pathophysiologically based treatment interventions in schizophrenia. Nat Med. 2006; 12(9):1016-1022. [PubMed: 16960576]

3. McGuire P, Howes OD, Stone J, Fusar-Poli P. Functional neuroimaging in schizophrenia: diagnosis and drug discovery. Trends Pharmacol Sci. 2008; 29(2):91-98. [PubMed: 18187211]

4. Mackay AV, Iversen LL, Rossor M, Spokes E, Bird E, Arregui A, Creese I, Synder SH. Increased brain dopamine and dopamine receptors in schizophrenia. Arch Gen Psychiatry. 1982; 39(9):991997. [PubMed: 7115016]

5. Lee T, Seeman P. Elevation of brain neuroleptic/dopamine receptors in schizophrenia. Am J Psychiatry. 1980; 137(2):191-197. [PubMed: 6101525]

6. Bird ED, Spokes EG, Iversen LL. Increased dopamine concentration in limbic areas of brain from patients dying with schizophrenia. Brain. 1979; 102(2):347-360. [PubMed: 455044]

7. Zakzanis KK, Hansen KT. Dopamine D2 densities and the schizophrenic brain. Schizophr Res. 1998; 32(3):201-206. [PubMed: 9720125]

8. Widerlov E. A critical appraisal of CSF monoamine metabolite studies in schizophrenia. Ann N Y Acad Sci. 1988; 537:309-323. [PubMed: 2462396]

9. Howes OD, Egerton A, Allan V, McGuire P, Stokes P, Kapur S. Mechanisms underlying psychosis and antipsychotic treatment response in schizophrenia: insights from PET and SPECT imaging. Curr Pharm Des. 2009; 15(22):2550-2559. [PubMed: 19689327]

10. Lyon GJ, Abi-Dargham A, Moore H, Lieberman JA, Javitch JA, Sulzer D. Presynaptic Regulation of Dopamine Transmission in Schizophrenia. Schizophr Bull. 2011; 37(1):108-17. [PubMed: 19525353]

11. Davis KL, Kahn RS, Ko G, Davidson M. Dopamine in schizophrenia: a review and reconceptualization. Am J Psychiatry. 1991; 148(11):1474-1486. [PubMed: 1681750]

12. Abi-Dargham A. Do we still believe in the dopamine hypothesis? New data bring new evidence. Int J Neuropsychopharmacol. 2004; 7(Suppl 1):S1-5. [PubMed: 14972078]

13. Howes OD, Kapur S. The dopamine hypothesis of schizophrenia: version III--the final common pathway. Schizophr Bull. 2009; 35(3):549-562. [PubMed: 19325164]

14. Farde L, Wiesel FA, Stone-Elander S, Halldin C, Nordstrom AL, Hall H, Sedvall G. D2 dopamine receptors in neuroleptic-naive schizophrenic patients. A positron emission tomography study with [11C]raclopride. Arch Gen Psychiatry. 1990; 47(3):213-219. [PubMed: 1968328]

15. Wong DF, Wagner HN Jr. Tune LE, Dannals RF, Pearlson GD, Links JM, Tamminga CA, Broussolle EP, Ravert HT, Wilson AA, Toung JK, Malat J, Williams JA, O’Tuama LA, Snyder SH, Kuhar MJ, Gjedde A. Positron emission tomography reveals elevated D2 dopamine receptors in drug-naive schizophrenics. Science. 1986; 234(4783):1558-1563. [PubMed: 2878495]

16. Howes OD, Montgomery AJ, Asselin MC, Murray RM, Grasby PM, McGuire PK. Molecular imaging studies of the striatal dopaminergic system in psychosis and predictions for the prodromal phase of psychosis. Br J Psychiatry. 2007; 191(Suppl 51):s13-18.

17. Laruelle M, Abi-Dargham A. Dopamine as the wind of the psychotic fire: new evidence from brain imaging studies. J Psychopharmacol. 1999; 13(4):358-371. [PubMed: 10667612] 
18. Meisenzahl EM, Schmitt GJ, Scheuerecker J, Moller HJ. The role of dopamine for the pathophysiology of schizophrenia. Int Rev Psychiatry. 2007; 19(4):337-345. [PubMed: 17671867]

19. Reith J, Benkelfat C, Sherwin A, Yasuhara Y, Kuwabara H, Andermann F, Bachneff S, Cumming P, Diksic M, Dyve SE, Etienne P, Evans AC, Lal S, Shevell M, Savard G, Wong DF, Chouinard G, Gjedde A. Elevated dopa decarboxylase activity in living brain of patients with psychosis. Proc Natl Acad Sci U.S.A. 1994; 91(24):11651-11654. [PubMed: 7972118]

20. Laruelle M. Imaging dopamine transmission in schizophrenia. A review and meta-analysis. Q J Nucl.Med. 1998; 42(3):211-221. [PubMed: 9796369]

21. Smith Y, Kieval JZ. Anatomy of the dopamine system in the basal ganglia. Trends Neurosci. 2000; 23(Suppl 10):S28-S33. [PubMed: 11052217]

22. Egerton A, Demjaha A, McGuire P, Mehta MA, Howes OD. The test-retest reliability of $18 \mathrm{~F}-$ DOPA PET in assessing striatal and extrastriatal presynaptic dopaminergic function. Neuroimage. 2009; 50(2):524-531. [PubMed: 20034580]

23. Mawlawi O, Martinez D, Slifstein M, Broft A, Chatterjee R, Hwang DR, Huang Y, Simpson N, Ngo K, Van Heertum R, Laruelle M. Imaging human mesolimbic dopamine transmission with positron emission tomography: I. Accuracy and precision of $\mathrm{D}(2)$ receptor parameter measurements in ventral striatum. J Cereb Blood Flow Metab. 2001; 21(9):1034-1057. [PubMed: 11524609]

24. Howes OD, Bose SK, Turkheimer F, Valli I, Egerton A, Valmaggia LR, Murray RM, McGuire P. Dopamine synthesis capacity before onset of psychosis: a prospective [18]-DOPA PET imaging study. Am J Psychiatry. 2011; 168(12):1311-7. [PubMed: 21768612]

25. Laruelle M, Abi-Dargham A, Gil R, Kegeles L, Innis R. Increased dopamine transmission in schizophrenia: relationship to illness phases. Biol Psychiatry. 1999; 46(1):56-72. [PubMed: 10394474]

26. Doudet DJ, Holden JE. Raclopride studies of dopamine release: dependence on presynaptic integrity. Biol Psychiatry. 2003; 54(11):1193-1199. [PubMed: 14643086]

27. Cumming P, Boyes BE, Martin WR, Adam M, Grierson J, Ruth T, McGeer EG. The metabolism of [18F]6-fluoro-L-3,4-dihydroxyphenylalanine in the hooded rat. J Neurochem. 1987; 48(2):601608. [PubMed: 3098920]

28. Matsumura K, Bergström M, Onoe H, Takechi H, Westerberg G, Antoni G, Bjurling P, Jacobson GB, Långström B, Watanabe Y. In vitro positron emission tomography (PET): use of positron emission tracers in functional imaging in living brain slices. Neurosci Res. 1995; 22(2):219-229. [PubMed: 7566703]

29. Piccini P, Pavese N, Brooks DJ. Endogenous dopamine release after pharmacological challenges in Parkinson's disease. Ann Neurol. 2003; 53(5):647-653. [PubMed: 12730999]

30. Farde L, Wiesel FA, Halldin C, Sedvall G. Central D2-dopamine receptor occupancy in schizophrenic patients treated with antipsychotic drugs. Arch.Gen.Psychiatry. 1988; 45(1):71-76. [PubMed: 2892477]

31. Hedges, LV.; Olkin, L. Statistical methods for meta-analysis. Academic Press; San Diego, CA: 1985.

32. Hedges LV, Vevea JL. Fixed and random effects models in meta-analysis. Psychological Methods. 1998; 3(4):486-504.

33. Raudenbush, SW. Analysing effect sizes: random effects models. In: Cooper, H.; Hedges, LV.; Valentine, JC., editors. The handbook of research synthesis and meta-analysis. 2nd ed.. Russell Sage Foundation; New York, NY: 2009. p. 295-315.

34. Higgins JP, Thompson SG, Deeks JJ, Altman DG. Measuring inconsistency in meta-analyses. Br Med J. 2003; 327(7414):557-560. [PubMed: 12958120]

35. Abi-Dargham A, Giessen EV, Slifstein M, Kegeles LS, Laruelle M. Baseline and AmphetamineStimulated Dopamine Activity Are Related in Drug-Naive Schizophrenic Subjects. Biol Psychiatry. 2009; 65(12):1091-3. [PubMed: 19167701]

36. Abi-Dargham A, Rodenhiser J, Printz D, Zea-Ponce Y, Gil R, Kegeles LS, Weiss R, Cooper TB, Mann JJ, Van Heertum RL, Gorman JM, Laruelle M. Increased baseline occupancy of D2 receptors by dopamine in schizophrenia. Proc Natl Acad Sci U S A. 2000; 97(14):8104-8109. [PubMed: 10884434] 
37. Shotbolt P, Stokes PR, Owens SF, Toulopoulou T, Picchioni MM, Bose SK, Murray RM, Howes OD. Striatal dopamine synthesis capacity in twins discordant for schizophrenia. Psychol Med. 2011; 41(11):2331-2338. [PubMed: 21426628]

38. Tune LE, Wong DF, Pearlson G, Strauss M, Young T, Shaya EK, Dannals RF, Wilson AA, Ravert HT, Sapp J, Cooper T, Chase GA, Wagner HN. Dopamine D2 receptor density estimates in schizophrenia: a positron emission tomography study with 11C-N-methylspiperone. Psychiatry Res. 1993; 49(3):219-237. [PubMed: 7909948]

39. Knable MB, Egan MF, Heinz A, Gorey J, Lee KS, Coppola R, Weinberger DR. Altered dopaminergic function and negative symptoms in drug-free patients with schizophrenia. [123I]iodobenzamide SPECT study. Br J Psychiatry. 1997; 171:574-577. [PubMed: 9519100]

40. Abi-Dargham A, Mawlawi O, Lombardo I, Gil R, Martinez D, Huang Y, Hwang DR, Keilp J, Kochan L, Van Heertum R, Gorman JM, Laruelle M. Prefrontal dopamine D1 receptors and working memory in schizophrenia. J Neurosci. 2002; 22(9):3708-3719. [PubMed: 11978847]

41. Karlsson P, Farde L, Halldin C, Sedvall G. PET study of D(1) dopamine receptor binding in neuroleptic-naive patients with schizophrenia. Am J Psychiatry. 2002; 159(5):761-767. [PubMed: 11986129]

42. Okubo Y, Suhara T, Suzuki K, Kobayashi K, Inoue O, Terasaki O, Someya Y, Sassa T, Sudo Y, Matsushima E, Iyo M, Tateno Y, Toru M. Decreased prefrontal dopamine D1 receptors in schizophrenia revealed by PET. Nature. 1997; 385(6617):634-636. [PubMed: 9024661]

43. Abi-Dargham A, Xu X, Thompson JL, Gil R, Kegeles LS, Urban NB, Narendran R, Hwang DR, Laruelle M, Slifstein M. Increased prefrontal cortical D1 receptors in drug naive patients with schizophrenia: a PET study with [11C]NNC112. J Psychopharmacology. Jul 18.2011 [Epub ahead of print] PMID: 21768159.

44. Kumakura Y, Cumming P. PET studies of cerebral levodopa metabolism: a review of clinical findings and modeling approaches. Neuroscientist. 2009; 15(6):635-650. [PubMed: 19793723]

45. Elkashef AM, Doudet D, Bryant T, Cohen RM, Li SH, Wyatt RJ. 6-(18)F-DOPA PET study in patients with schizophrenia. Positron emission tomography. Psychiatry Res. 2000; 100(1):1-11. [PubMed: 11090720]

46. Taylor SF, Koeppe RA, Tandon R, Zubieta JK, Frey KA. In vivo measurement of the vesicular monoamine transporter in schizophrenia. Neuropsychopharmacology. 2000; 23(6):667-675. [PubMed: 11063922]

47. Zubieta JK, Taylor SF, Huguelet P, Koeppe RA, Kilbourn MR, Frey KA. Vesicular monoamine transporter concentrations in bipolar disorder type I, schizophrenia, and healthy subjects. Biol Psychiatry. 2001; 49(2):110-116. [PubMed: 11164757]

48. Bogerts B, Hantsch J, Herzer M. A morphometric study of the dopamine-containing cell groups in the mesencephalon of normals, Parkinson patients, and schizophrenics. Biol Psychiatry. 1983; 18(9):951-969. [PubMed: 6640008]

49. Kumakura Y, Cumming P, Vernaleken I, Buchholz HG, Siessmeier T, Heinz A, Kienast T, Bartenstein P, Gründer G. Elevated [18F]fluorodopamine turnover in brain of patients with schizophrenia: an [18F]fluorodopa/positron emission tomography study. J Neurosci. 2007; 27(30): 8080-8087. [PubMed: 17652599]

50. Wong DF, Gjedde A, Wagner HN Jr. Quantification of neuroreceptors in the living human brain. I. Irreversible binding of ligands. J Cereb Blood Flow Metab. 1986; 6(2):137-146. [PubMed: 2937794]

51. Ishiwata K, Ogi N, Hayakawa N, Umegaki H, Nagaoka T, Oda K, Toyama H, Endo K, Tanaka A, Senda M. Positron emission tomography and ex vivo and in vitro autoradiography studies on dopamine D2-like receptor degeneration in the quinolinic acid-lesioned rat striatum: comparison of [11C]raclopride, [11C]nemonapride and [11C]N-methylspiperone. Nucl Med Biol. 2002; 29(3): 307-316. [PubMed: 11929700]

52. Ishiwata K, Hayakawa N, Ogi N, Oda K, Toyama H, Endo K, Tanaka A, Senda M. Comparison of three PET dopamine D2-like receptor ligands, [11C]raclopride, [11C]nemonapride and [11C]Nmethylspiperone, in rats. Ann Nucl Med. 1999; 13(3):161-167. [PubMed: 10435376] 
53. Bischoff S, Gunst F. Distinct binding patterns of $[3 \mathrm{H}]$ raclopride and $[3 \mathrm{H}]$ spiperone at dopamine D2 receptors in vivo in rat brain. Implications for pet studies. J Recept Signal Transduct Res. 1997; 17(1-3):419-431. [PubMed: 9029505]

54. Chugani DC, Ackermann RF, Phelps ME. In vivo [3H]spiperone binding: evidence for accumulation in corpus striatum by agonist-mediated receptor internalization. J Cereb Blood Flow Metab. 1988; 8(3):291-303. [PubMed: 2966803]

55. Sun W, Ginovart N, Ko F, Seeman P, Kapur S. In vivo evidence for dopamine-mediated internalization of D2-receptors after amphetamine: differential findings with $[3 \mathrm{H}]$ raclopride versus [3H]spiperone. Mol Pharmacol. 2003; 63(2):456-462. [PubMed: 12527818]

56. Guo N, Guo W, Kralikova M, Jiang M, Schieren I, Narendran R, Slifstein M, Abi-Dargham A, Laruelle M, Javitch JA, Rayport S. Impact of D2 receptor internalization on binding affinity of neuroimaging radiotracers. Neuropsychopharmacology. 2010; 35(3):806-817. [PubMed: 19956086]

57. Hartvig P, Torstenson R, Tedroff J, Watanabe Y, Fasth KJ, Bjurling P, Långström B. Amphetamine effects on dopamine release and synthesis rate studied in the Rhesus monkey brain by positron emission tomography. J Neural Transm. 1997; 104(4-5):329-339. [PubMed: 9295169]

58. Snyder SH. The dopamine hypothesis of schizophrenia: focus on the dopamine receptor. Am J Psychiatry. 1976; 133(2):197-202. [PubMed: 1251927]

59. Howes O, Bose S, Turkheimer F, Valli I, Egerton A, Stahl D, Valmaggia L, Allen P, Murray R, McGuire P. Progressive increase in striatal dopamine synthesis capacity as patients develop psychosis: a PET study. Mol Psychiatry. 2011; 16(9):885-6. [PubMed: 21358709]

60. Heinz A, Romero B, Gallinat J, Juckel G, Weinberger DR. Molecular brain imaging and the neurobiology and genetics of schizophrenia. Pharmacopsychiatry. 2003; 36(Suppl 3):S152-157. [PubMed: 14677072]

61. Fusar-Poli P, Howes OD, Allen P, Broome M, Valli I, Asselin MC, Grasby PM, McGuire PK. Abnormal frontostriatal interactions in people with prodromal signs of psychosis: a multimodal imaging study. Arch Gen Psychiatry. 2010; 67(7):683-691. [PubMed: 20603449]

62. Meyer-Lindenberg A, Miletich RS, Kohn PD, Esposito G, Carson RE, Quarantelli M, Weinberger DR, Berman KF. Reduced prefrontal activity predicts exaggerated striatal dopaminergic function in schizophrenia. Nat Neurosci. 2002; 5(3):267-271. [PubMed: 11865311]

63. Kegeles LS, Abi-Dargham A, Zea-Ponce Y, Rodenhiser-Hill J, Mann JJ, Van Heertum RL, Cooper TB, Carlsson A, Laruelle M. Modulation of amphetamine-induced striatal dopamine release by ketamine in humans: implications for schizophrenia. Biol Psychiatry. 2000; 48(7):627-640. [PubMed: 11032974]

64. Lodge DJ, Grace AA. Aberrant hippocampal activity underlies the dopamine dysregulation in an animal model of schizophrenia. J Neurosci. 2007; 27(42):11424-11430. [PubMed: 17942737]

65. Stone JM, Howes OD, Egerton A, Kambeitz J, Allen P, Lythgoe DJ, O'Gorman RL, McLean MA, Barker GJ, McGuire P. Relationship between glutamate and dopamine in individuals with prodromal symptoms of schizophrenia. Biol Psychiatry. 2010; 68(7):599-602. [PubMed: 20638047]

66. Staley JK, Krishnan-Sarin S, Zoghbi S, Tamagnan G, Fujita M, Seibyl JP, Maciejewski PK, O'Malley S, Innis RB. Sex differences in [123I]beta-CIT SPECT measures of dopamine and serotonin transporter availability in healthy smokers and nonsmokers. Synapse. 2001; 41(4):275284. [PubMed: 11494398]

67. Howes OD, Montgomery AJ, Asselin MC, Murray RM, Valli I, Tabraham P, Bramon-Bosch E, Valmaggia L, Johns L, Broome M, McGuire PK, Grasby PM. Elevated striatal dopamine function linked to prodromal signs of schizophrenia. Arch Gen Psychiatry. 2009; 66(1):13-20. [PubMed: 19124684]

68. Kegeles LS, Abi-Dargham A, Frankle WG, Gil R, Cooper TB, Slifstein M, Hwang DR, Huang Y, Haber SN, Laruelle M. Increased synaptic dopamine function in associative regions of the striatum in schizophrenia. Arch Gen Psychiatry. 2010; 67(3):231-239. [PubMed: 20194823]

69. Seeman P, Lee T, Chau-Wong M, Wong K. Antipsychotic drug doses and neuroleptic/dopamine receptors. Nature. 1976; 261(5562):717-719. [PubMed: 945467] 
70. Ginovart N, Wilson AA, Hussey D, Houle S, Kapur S. D2-receptor upregulation is dependent upon temporal course of D2-occupancy: a longitudinal [11C]-raclopride PET study in cats. Neuropsychopharmacology. 2009; 34(3):662-671. [PubMed: 18688210]

71. Silvestri S, Seeman MV, Negrete JC, Houle S, Shammi CM, Remington GJ, Kapur S, Zipursky RB, Wilson AA, Christensen BK, Seeman P. Increased dopamine D2 receptor binding after longterm treatment with antipsychotics in humans: a clinical PET study. Psychopharmacology. 2000; 152(2):174-180. [PubMed: 11057521]

72. Hollister LE, Krieger GE, Kringel A, Roberts RH. Treatment of chronic schizophrenic reactions with reserpine. Ann N Y Acad Sci. 1955; 61(1):92-100. [PubMed: 14377276]

73. Demjaha A, Murray RM, Kapur S, Howes OD. Dopaminergic function in treatment resistant schizophrenia. Schizophr Bull. 2011; S10:s10-s11.

74. Seeman P. All roads to schizophrenia lead to dopamine supersensitivity and elevated dopamine D2(high) receptors. CNS Neurosci Ther. 2011; 17(2):118-132. [PubMed: 20560996]

75. Tamminga CA, Schaffer MH, Smith RC, Davis JM. Schizophrenic symptoms improve with apomorphine. Science. 1978; 200(4341):567-568. [PubMed: 347574]

76. Graff-Guerrero A, Mizrahi R, Agid O, Marcon H, Barsoum P, Rusjan P, Wilson AA, Zipursky R, Kapur S. The dopamine D2 receptors in high-affinity state and D3 receptors in schizophrenia: a clinical [11C]-(+)-PHNO PET study. Neuropsychopharmacology. 2009; 34(4):1078-1086. [PubMed: 18987627]

77. Heinz A, Saunders RC, Kolachana BS, Jones DW, Gorey JG, Bachevalier J, Weinberger DR. Striatal dopamine receptors and transporters in monkeys with neonatal temporal limbic damage. Synapse. 1999; 32(2):71-79. [PubMed: 10231127] 

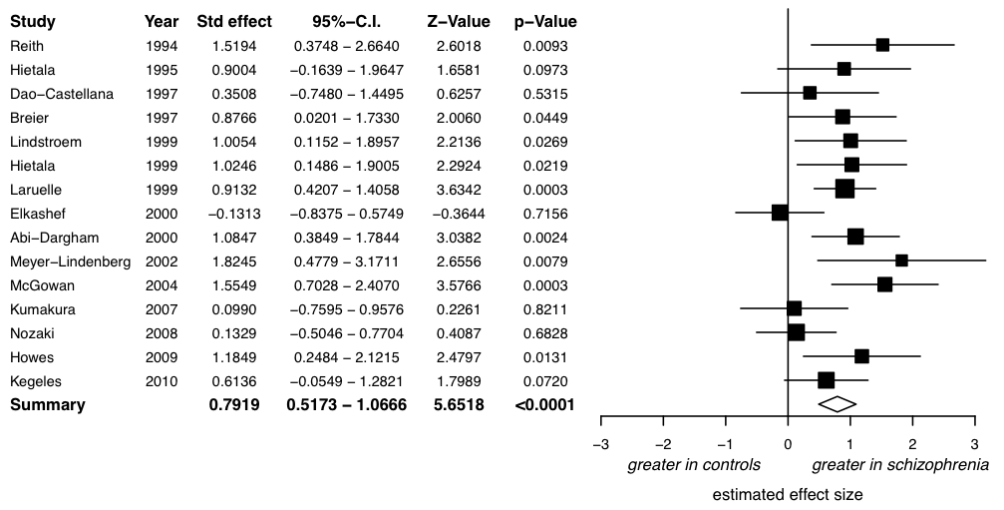

Figure 1.

Studies of presynaptic dopaminergic function: Forrest plot showing the effect size and $95 \%$ confidence intervals of the difference between patients with schizophrenia and controls by study. There was evidence of a significant elevation in schizophrenia with a summary effect size of $d=0.79$. 


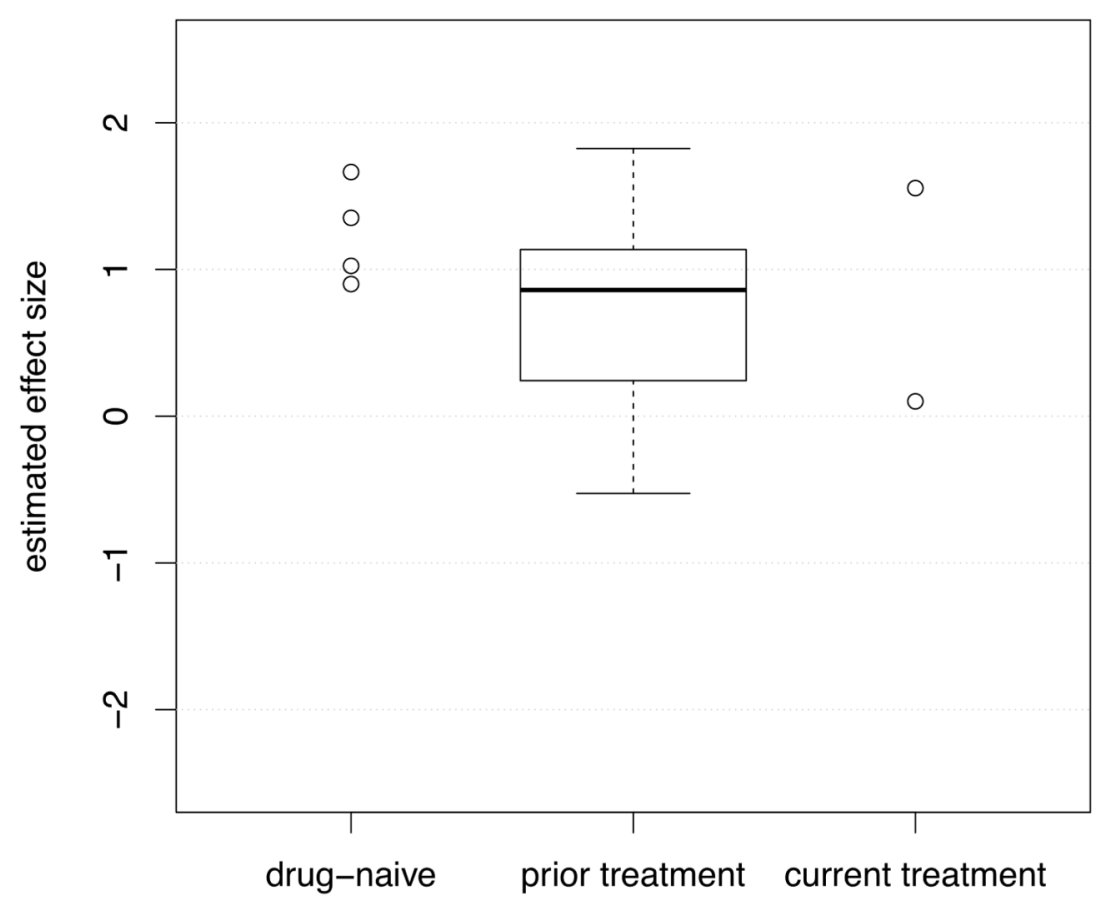

Figure 2.

Studies of presynaptic dopaminergic function: the effect sizes for studies by antipsychotic treatment history (in the boxplot the band is the median and the whiskers indicate the lowest and highest data points that are within $1.5 *$ the interquartile range, and data outside this range (circles if present) are regarded as potential outliers) 

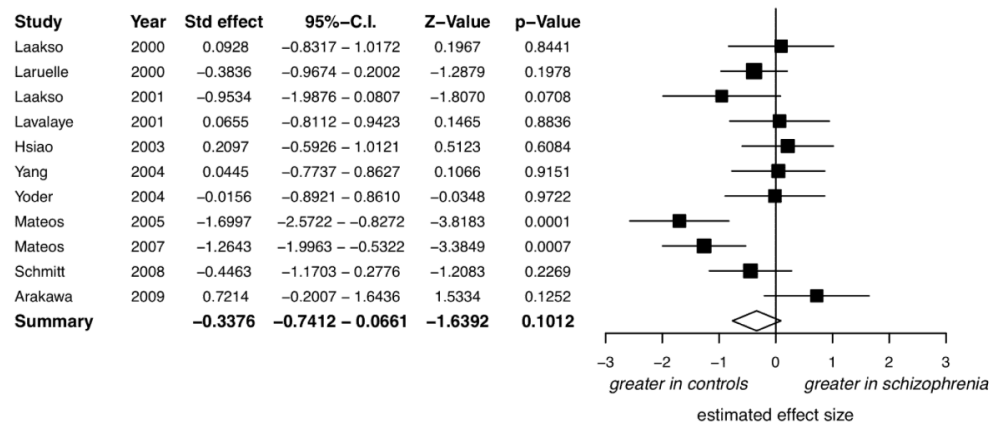

Figure 3.

Studies of dopamine transporter availability: Forrest plot showing the effect size and $95 \%$ confidence intervals of the effect sizes by study. The $95 \%$ confidence interval for the summary effect size (lozenge, $d=0.34$ ) includes 0 , indicating no significant difference between patients with schizophrenia and controls. 


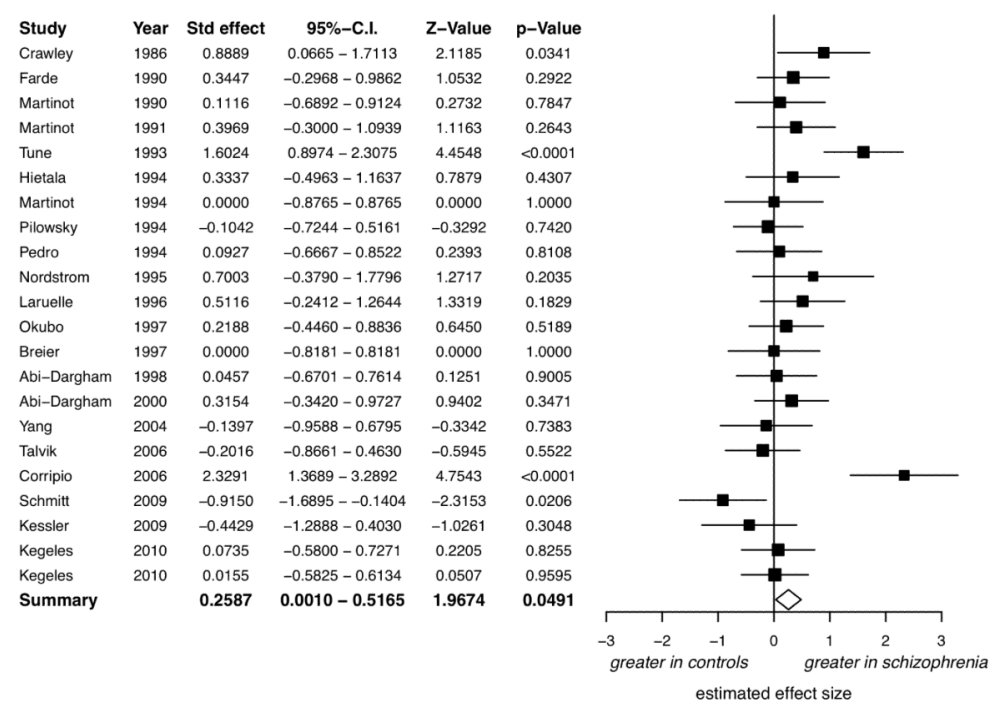

Figure 4.

Studies of D2/3 receptor availability: Forrest plot showing the effect size and $95 \%$ confidence intervals of the effect sizes by study. There was evidence of a small increase in D2 receptor availability in schizophrenia with a summary effect size (lozenge) of $d=0.26$. 


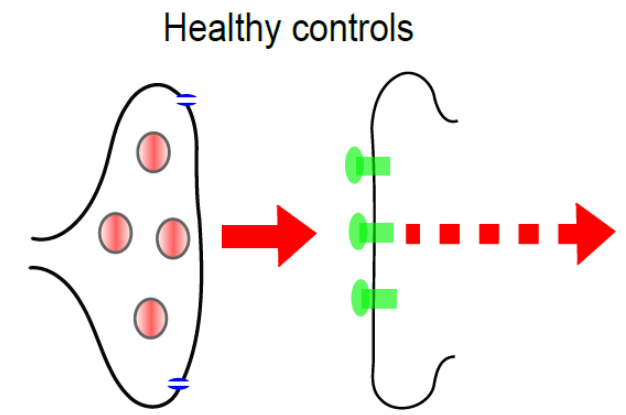

Schizophrenia

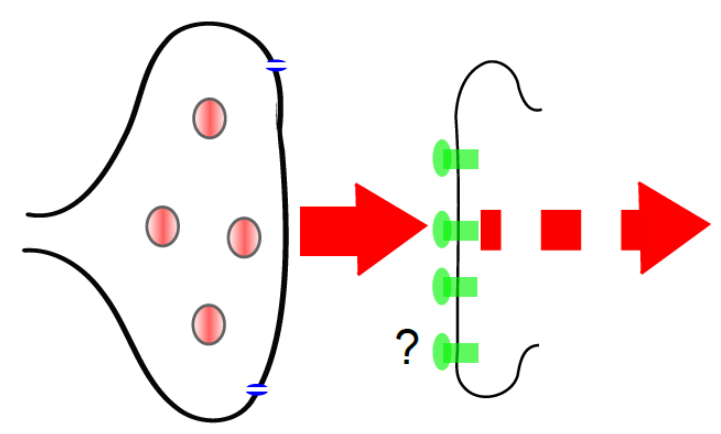

Figure 5.

Schematic diagram summarising the findings from our meta-analyses of dopamine imaging findings in schizophrenia showing that the major abnormality is increased presynaptic dopamine synthesis capacity and release (not shown to scale). 